\title{
A Mucinous Colon Adeno Carcinoma Relapse 20 years after Primary Tumour Treatment? A Case Report and Mini Review on the Role of FDG- PET/CT in Mucinous Cancers
}

\author{
Miguel Berzosa Sánchez ${ }^{1 *}$, Montserrat Llobera Serentill² ${ }^{2}$ Valeri Rodríguez Guzmán ${ }^{1}$ and Ángela Moreno \\ Martí1 \\ ${ }^{1}$ Medical Oncologist, Verge de la Cinta Hospital, Spain \\ ${ }^{2}$ Chief of Medical Oncology Department, Verge de la Cinta Hospital, Spain
}

Submission: October 31, 2017; Published: November 27, 2017

*Corresponding author: Miguel Berzosa Sánchez, Medical Oncologist, Gastrointestinal Tumours Unit in Hospital Verge de la Cinta, C/ Esplanetes, 14-43500, Tortosa, Tarragona, Spain, Tel: +34-977-51-91-00; Email: berzosa.miguel@gmail.com

\begin{abstract}
Background: Colorectal Cancer (CRC) is the third most common cancer worldwide. Despite adequate treatment late relapses (beyond 5 years follow-up) may occur. FDG- PET/TC may be useful in this setting.

Case: A 48 year-old women underwent curative treatment for a stage IIIA mucinous colon cancer with signet-cell variant. 20 years later, a bulky retroperitoneal mass is evidenced by CT scan in the context of a new-onset toxic syndrome and hip pain. First biopsy is diagnostic for carcinoma and a FDG- PET/TC is performed with the aim to identify a primary tumour and rule out further disease and turns out futile. A second biopsy of the mass is diagnostic for mucinous adenocarcinoma of colorectal origin. Deemed unrespectable, palliative treatment is offered and the patient dies 13 months after diagnosis.
\end{abstract}

Conclusion: Despite its usefulness in most cancers, FDG- PET/CT should be avoided in mucinous cancers.

Keywords: Mucinous neoplasms; Colon cancer; Long-term recurrence; Diagnosis; Imaging; FDG-PET/CT

Abbreviations: CRC: Colorectal Cancer; FDG: ${ }^{18}$ Fluoro-deoxy-glucose; FDG-PET/CT: Combined ${ }^{18}$ Fluorodeoxyglucose Positron Emission Tomography and Computed Tomography; CT: Computed Tomography

\section{Introduction}

Colorectal cancer (CRC) is the third most commonly diagnosed malignancy and the fourth cause of death from cancer worldwide [1]. Despite adequate surgical and adjuvant treatment (when indicated), secondary tumours and long-term recurrences may occur [2] but few data are available on late-recurrences beyond 10 years follow-up. Therefore, further surveillance is not currently recommended on a general basis. Only 30\% of relapses occur 24 months after completion of primary tumour treatment and relapses after this period are usually associated to low- risk early cancers such as T1-T2 and G1 cancers, harbouring a better prognosis than early relapses [3,4]. On the opposite, T3-T4 and G2-3 tumours tend to relapse earlier. Regarding histology, mucinous-type does not seem to affect the time of relapse but when it occurs, prognostic is poor with survival not exceeding 2 years [5]. The role of imaging techniques is welldefined in diagnosing relapses from colorectal cancer and CT scan has a crucial role. FDG-PET/CT may also be helpful but it has some limitations [6]. Herein we discuss its usefulness in this context regarding a second mucinous malignancy 20 years after treatment of a primary signet-cell colon cancer with curative intent.

\section{Case Report}

We introduce a 48 year-old female with morbid-obesity; arterial hypertension and type- 2 diabetes mellitus adequately controlled with oral medication that underwent in 1996 a right hemicolectomyin which pathology study revealed a highgrade mucinous adenocarcinoma with signet-cell variant 
invading through the muscularispropia and into the subserosal adipose tissue. The margins were negative for tumour and no lymphovascular or perineural invasion was noted. Hence, she was staged as pT3, pN1 (2/24) pMx-stage IIIA. Microsatellite instability testing showed the preservation of MLH1, PMS2, MSH2 and MSH6 proteins by IHC and PCR, So Lynch Syndrome was ruled out. Standard adjuvant treatment with chemotherapy (5-FU/ leucovorin) was completed full-dose for 6 months and routine follow-up with CT scan, tumour markers (CEA and Ca 19.9) and colonoscopy (last one in 2012) was performed for five years, showing no evidence of disease.

In march 2016 she presented with a new-onset progressive six-month right hip pain with irradiation to anterior ipsilateral limb as well as a toxic syndrome leading to up to a $30 \mathrm{~kg}$ loss of weight. No B symptoms were reported. Initial workup with tumour markers and CT scan (chest, abdomen and pelvis) revealed a $10 \times 6 \mathrm{~cm}$ retroperitoneal bulky mass with diffuse right psoas, vertebral (L1, right-side of the corpus vertebrae) and vascular infiltration(cava vein and aorta) which was suspicious of malignant lymph-node involvement. A suspicious mediastinal $18 \mathrm{~mm}$ (short axis) lymphadenopathy was also described. CEA was slightly raised $(5.42 \mathrm{ng} / \mathrm{mL})$ whereas levels of other tumour markers (ca 19.9, Ca 125, Ca 15.3, b2-microglobulin) remained in normal range. First biopsy from the corpus vertebrae of L1 showed metastasis from carcinoma but no further information regarding its origins could be added due to scarce cellularity (Figure 1).

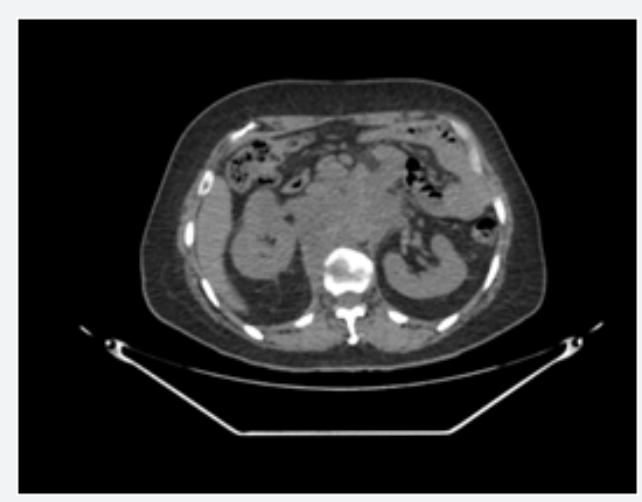

Figure 1: CT scan showing the bulky retroperitoneal mass with diffuse vascular, vertebral and visceral infiltration.

A FDG-PET/TC was performed in order to rule out distant metastasis and search for a primary tumour. This revealed the bulky mass described on CT with a predominantly cystic/necrotic appearance and mild hyper metabolism in its walls as well as a hyper metabolic (SUV max $4.3 \mathrm{~g} / \mathrm{mL}$ ) nodular area next to the head of pancreas. No distant lesions suggesting metastasisnor a primary tumour were identified. Thereafter, a second CT guided gross tumour biopsy of the retroperitoneal mass was performed. The pathology report described a mucinous adenocarcinoma positive for CDX2 and CK20 and negative for PAX8, WT1 and CK7, consistent with metastasis from a colorectal primary tumour.
Additional genomic testing showed a G12Dmutation in exon 2 of k-ras gene. The case was discussed in our Tumour Board and under the suspicion of are current colon cancer it was deemed unrespectable so sequential external-beam radiotherapy over L1 and chemotherapy were offered with palliative intent. First line chemotherapy witha modified oxaliplatin/5-fluorouracil/ leucovorin(mFOLFOX6)- bevacizumab regimen was completed for 8 cycles ( 4 months) with stable disease as best response and due to neurotoxicity followed by capecitabine-bevacizumab for 2 additional months after which local progression was reported. FOLFIRI was chosen as the second- line treatment (due to high vascular risk, bevacizumab was not maintained in this second line) and she received 11 cycles (almost 6 months) with stable disease as best response. Thereafter, progressive performance status deterioration led us to stop active treatment and she was offered best supportive care in hospice. She finally died in May 2017, 13 months after diagnosis (Figure 2).

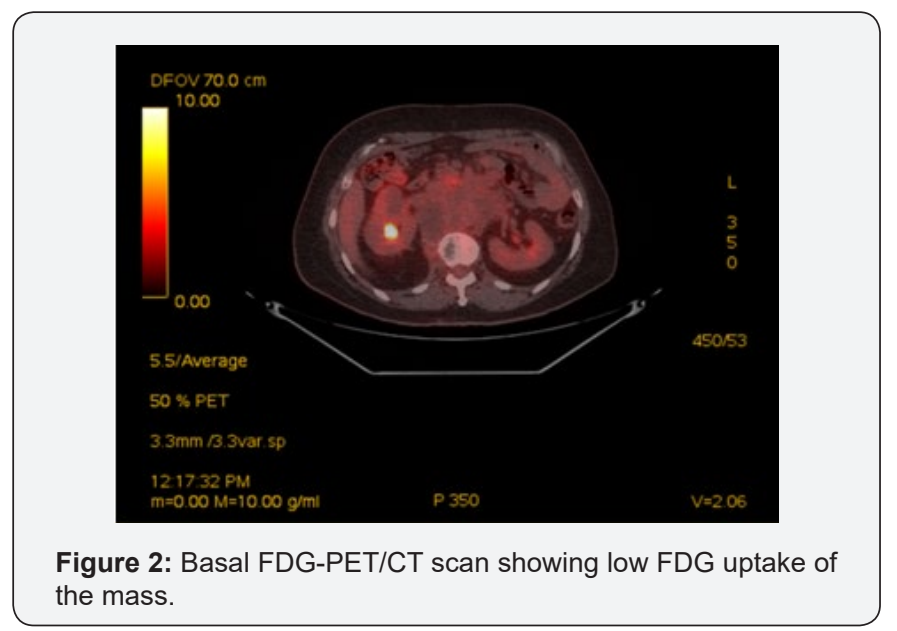

\section{Discussion}

According to the standard guidelines for postoperative follow-up for CRC, published by the National Comprehensive Cancer Network Clinical Practice in OncologyTM in 2017 [7], a 5-year follow up program should be undertaken postoperatively in order to improve survival by detecting recurrences and metachronous colon cancers earlier, when they are at a curable stage. This should include documentation of the patient's medical history, physical examination, measurement of carcinoembryonic antigen, colonoscopies examination and computed tomography.

It has been reported that $93-95 \%$ of CRC relapses occur within 5 years of primary tumour resection. Early recurrences before 24 months are associated with advanced pathological stage, high-grade histology and other high grade features and they may show worse prognosis. T1-T2 and G1 may be predictors for relapses beyond 24 months and prognosis is better. A previous methodological study estimated the timescale for statistical cure in colon cancer at 9.3years, defined as the moment at which the excess risk of death linked to colorectal cancer disappears. This is confirmed by a recent study [2] showing that late relapses between 5 and 10 years can still occur in as much as 1 in 17 
patients, especially in a context of perforated primary tumour. Therefore, regular follow-up beyond 5 years and up to 10years may be justified on an individual basis.

Our patient presented with a diagnosis of metastatic colorectal mucinous adenocarcinoma 20 years after completing curative treatment for a former mucinous colon cancer with signet-cell variant, which is a very aggressive histological type featuring early-relapses and dismal prognosis. Based on a MEDLINE literature search spanning the period between January 1966 and December 2016 no relapses of a colorectal cancer beyond 13 years [8] have ever been documented. This raised the question on if our findings were actually a true relapse, appealing to the mucinous histology shared by both tumours versus a metachronous second malignancy of the colon. The fact that the vast majority of malignant cancer phenotypes exhibit an increased glucose uptake (Warburg effect) is the rationale for the use of FDG as radiotracer and makes it a potentially more sensitive tool for detecting tumours when compared to other techniques such as the CT scan [9].

Since its introduction in the early nineties, FDG-PET/TC has become a cornerstone in many oncological procedures such as tumour staging and restaging, treatment efficacy assessment during or after treatment end and radiotherapy planning. It is also well described the higher potential of FGD-PET/TC to depict a primary unknown tumour. As an example, in one study, 33\% of primary tumours were spotted by FDG-PET/TC versus 18\% and $24 \%$ of, respectively, CT scan and FDG PET alone [10]. Warburg effect also explains its limitations in mucinous neoplasms, where glucose uptake may be diluted by the extracellular amounts of mucin and relative ehipocellularity. Hence, lower peaks of standardized uptake values are obtained when compared to other histologies [9], leading to falsely- negative results.

At the time of ordering this test, information regarding the definitive histology was not available and the goal was completing diagnosis by detecting a primary tumour and rule out other sites of metastasis. Not surprisingly, information provided by CT scan was not improved by FDG-PET/TC and hence, response assessments were performed by timely CT scans [11]. Nevertheless, a colonoscopy was not performed due to futility since unrespectability and the clear diagnosis of a colorectal origin by immune histo chemistry and genetics, allowing us to select and start the best palliative chemotherapy schedule. In conclusion, due to its limitations, FDG-PET/TC should not be performed in mucinous neoplasms. Colonoscopy remains the best test to rule out a metachronous colon cancer in this setting.

\section{Acknowledgement}

We would like to thank the patient and her family for their trust and for giving us the basis for this report.

\section{References}

1. GLOBOCAN 2012: Estimated cancer incidence, mortality and prevalence worldwide in 2012. International Agency for Research on Cancer.

2. Bouvier AM, Launoy G, Bouvier V, Rollot F, Manfredi S, et al. (2015) Incidence and patterns of late recurrences in colon cancer patients. Int J Cancer 137(9): 2133-2138.

3. Broadbridge VT, Karapetis CS, Beeke C, Woodman RJ, Padbury R, et al. (2013) Do metastatic colorectal cancer patients who present with late relapse after curative surgery have a better survival? Br J Cancer 109(5): 1338-1343.

4. Yazilitas D, Özdemir N, Yazıcı O, Hocazade C, Demirci NS, et al. (2016) The clinical and pathological features affecting the time of relapse in patients with early stage colorectal cancer. J Cancer Res Ther 12(4) $1257-1260$.

5. Lan YT, Chang SC, Yang SH, Lin CC, Wang HS, et al. (2014) Comparison of clinicopathological characteristics and prognosis between early and late recurrence after curative surgery for colorectal cancer. Am J Surg 207(6): 922-930.

6. Owen J, Shanaugh Mc, James S, Dushyant S, Michael A, et al. (2011) The Use of PET-CT in the assessment of patients with colorectal carcinoma. International Journal of Surgical Oncology 2011(2011): 1-14.

7. National Comprehensive Cancer Network (2017). NCCN Guidelines.

8. Huang YH Tsai HL, Chai CY, Wang JY (2010) Relapsed colon cancer patient presenting with hematuria 13 years after primary tumour resection: a case report. Kaohsiung J Med Sci 26(4): 211-216.

9. Thomas C, Sandip B, Gang C, Abass A (2010) FDG PET/CT in carcinoma of unknown primar. Eur J Nucl Med Mol Imaging 37(3): 635-644.

10. Gutzeit A, Antoch G, Kühl H, Egelhof T, Fischer M, et al. (2005) Unknown primary tumors: detection with dual-modality PET/ CT-initial experience. Radiology 234(1): 227-234.

11. Berger KL, Nicholson SA, Dehdashti F, Siegel BA (2000) FDG PET evaluation of mucinous neoplasms: correlation of FDG uptake with histopathologic features. AJR Am J Roentgenol 174(4): 1005-1008.

This work is licensed under Creative

Commons Attribution 4.0 License

DOI: $10.19080 /$ JTMP.2017.02.555590

\section{Your next submission with Juniper Publishers} will reach you the below assets

- Quality Editorial service

- Swift Peer Review

- Reprints availability

- E-prints Service

- Manuscript Podcast for convenient understanding

- Global attainment for your research

- Manuscript accessibility in different formats

( Pdf, E-pub, Full Text, Audio)

- Unceasing customer service

Track the below URL for one-step submission https://juniperpublishers.com/online-submission.php 